\title{
Impact of service improvement measures in a Victorian paediatric eating disorders program
}

\author{
Suba Rudolph ${ }^{1 *}$, Kellie Draffin ${ }^{2}$, Shea Edsall ${ }^{2}$, Saadia Oularbi ${ }^{1}$ \\ From 2014 ANZAED Conference: Driven Bodies Driven Brains \\ Fremantle, Australia. 22-23 August 2014
}

Three interventions were implemented to improve the paediatric eating disorders service at the Austin Hospital. The primary changes consisted of (i) introduction of a multidisciplinary initial assessment clinic, (ii) increased utilisation of Family-Based Treatment (FBT), and (iii) institution of aggressive inpatient feeding. A retrospective audit from 2011, 2012 and 2013 was conducted extracting medical records data. Service referrals doubled (28 in 2011 to 58 in 2013), associated with greater acuity at initial presentation $(50 \%$ vs $65 \%$ at $<90 \%$ expected body weight). The vast majority of admissions for medical stabilisation occurred within 2 weeks of presentation, reflecting this greater acuity ( $78 \%$ vs $92 \%$ ). Readmission rates halved (33\% to $17 \%)$ with a dramatic $75 \%$ reduction in patients requiring $>3$ admissions (33\% to $8 \%$ ). A $59 \%$ uptake of FBT by 2013 led to substantial improvements in weight restoration, from $46 \%$ to $71 \%$ of patients achieving $>90 \%$ expected body weight within 6 months. Increased utilisation of FBT is expected to further improve outcomes. FBT patients were more likely to achieve complete weight restoration (odds ratio 1.7). This escalating number and severity of service referrals demands additional resources and funding if the complex psychiatric and medical needs of our patients are to be adequately addressed.

This abstract was presented in the Service Initiatives: Child and Adolescent Refeeding and FBT stream of the 2014 ANZAED Conference.

\section{Authors' details}

'Department of Paediatrics, Austin Health, Melbourne, Australia. ${ }^{2}$ Department of Nutrition and Dietetics, Austin Health, Melbourne, Australia.
Published: 24 November 2014

doi:10.1186/2050-2974-2-S1-014

Cite this article as: Rudolph et al:: Impact of service improvement measures in a Victorian paediatric eating disorders program. Journal of Eating Disorders 2014 2(Suppl 1):014.

* Correspondence: suba.rudolph@gmail.com

${ }^{1}$ Department of Paediatrics, Austin Health, Melbourne, Australia

Full list of author information is available at the end of the article

Submit your next manuscript to BioMed Central and take full advantage of:

- Convenient online submission

- Thorough peer review

- No space constraints or color figure charges

- Immediate publication on acceptance

- Inclusion in PubMed, CAS, Scopus and Google Scholar

- Research which is freely available for redistribution
() Biomed Central 